\title{
Diphenylhydantoin and Potassium
}

\section{Transport in Isolated Nerve Terminals}

\author{
Antonio V. Escueta and Stanley H. Appei \\ From the Neurosciences Laboratories, Division of Neurology, Duke University \\ Medical Center, Durham, North Carolina 27706
}

A B S T R A C T The antiepileptic action of diphenylhydantoin (DPH) has been explained by two different theories: (a) that $\mathrm{DPH}$ stimulates the $\mathrm{Na}-\mathrm{K}$ pump; (b) that DPH specifically blocks the passive translocation of sodium. Since electrophysiological experiments have recently suggested abnormal synaptic mechanisms as the basis for epileptogenic discharges, the action of $\mathrm{DPH}$ on $\mathrm{K}$ transport within synaptic terminals isolated from "normal" rat brain cortex was examined directly. A rapid filtration technique was used to assess in vitro potassium transport within synaptosomes. In vivo $\mathrm{DPH}$ did not significantly change endogenous $\mathrm{K}$ content within synaptosomes. With sodium ( $50 \mathrm{~mm}$ ) and potassium (10 $\mathrm{mm}$ ) concentrations optimal for $\mathrm{Na}-\mathrm{K}$ pump activity, in vivo and in vitro $\mathrm{DPH}\left(10^{-4} \mathrm{M}\right)$ had minimal or no effects on total $\mathrm{K}$ uptake. DPH stimulated potassium uptake within synaptosomes under two situations : (a) at high sodium (50-100 mm) and low potassium (less than $2 \mathrm{~mm}$ ) concentrations; $(b)$ when synaptosomes were incubated with ouabain $\left(10^{-4} \mathrm{M}\right) 50$ $\mathrm{mM} \mathrm{Na}$ and $10 \mathrm{~mm} \mathrm{~K}$. In both situations, $\mathrm{K}$ was leaking out of synaptic terminals and the enhancement in net $K$ uptake roughly corresponded to the ouabain inhibitable segment. In the absence of ouabain, the stimulatory effects of DPH were not observed when $\mathrm{K}$ was $2 \mathrm{mM}$ or higher and when $\mathrm{Na}$ was $10 \mathrm{~mm}$ or lower. The stimulatory effects of in vitro DPH appeared over a range of concentrations from $10^{-4}$ to $10^{-10} \mathrm{M}$ while single intraperitoneal injections of DPH had to be administered for 2 days before its effects were observed on synaptosomal $\mathrm{K}$ transport. The present data provided direct evidence for DPH stimulation of active potassium transport within synaptosomes under ionic conditions simulating the depolarized state. At other ionic conditions, $\mathrm{DPH}$ had inhibitory or no effects on $\mathrm{K}$ uptake. Although the results do not specify whether the effects

Dr. Appel is the recipient of a Research Career Development Award from the U. S. Public Health Service.

Received for publication 15 December 1970. of $\mathrm{DPH}$ on the $\mathrm{Na}-\mathrm{K}$ pump are direct or indirect, they suggest that the action of $\mathrm{DPH}$ depends upon the state of the membrane and the specific ionic environment.

\section{INTRODUCTION}

Studies of the mechanism of action of diphenylhydantoin sodium $(\mathrm{DPH})^{1}$ have centered on the cation transport systems of excitable membranes of the cerebral cortex $(1,3)$. In whole cerebral cortical tissues, DPH prevented intracellular increase of $\mathrm{Na}$ caused by maximal electroshock seizures and increased the turnover of $\mathrm{Na}^{22}$ (1). Because of the close link established between membrane-oriented sodium-potassium-adenosinetriphosphatase (Na-K-ATPase) and cation transport (2), synaptosomal Na-K-ATPase was previously studied in an attempt to explain the $\mathrm{Na}$ extruding properties of $\mathrm{DPH}$. $\mathrm{DPH}$ stimulated synaptosomal $\mathrm{Na}-\mathrm{K}$-ATPase activity under conditions of high $\mathrm{Na}(100 \mathrm{~mm})$ and low $\mathrm{K}(0.2$ $\mathrm{mm}$ ) while it had minimal or no effects on enzyme activity with $50 \mathrm{~mm} \mathrm{Na}$ and $10 \mathrm{~mm} \mathrm{~K} \mathrm{(3).} \mathrm{On} \mathrm{the} \mathrm{basis}$ of these experiments, it was suggested that the anticonvulsant property of $\mathrm{DPH}$ may be related to its ability to enhance $\mathrm{Na}-\mathrm{K}-\mathrm{ATP}$ ase activity and increase $\mathrm{Na}$ efflux during depolarized states. This suggestion was based on several assumptions: (a) that synaptosome $\mathrm{Na}-\mathrm{K}$-ATPase is involved in the active transport of $\mathrm{K}$ and $\mathrm{Na}$; (b) that ion transport within synaptosomes is altered in convulsive states; and (c) that $\mathrm{DPH}$ reverses such alterations.

The present experiments directly examine $\mathrm{K}$ transport within synaptosomes isolated from "normal" rat cerebral cortex and investigate the action of $\mathrm{DPH}$ on such transport in vitro. In vivo and in vitro $\mathrm{DPH}$ stimulated active $\mathrm{K}$ transport within synaptosomes with 50 $100 \mathrm{~mm} \mathrm{Na}$ and less than $2 \mathrm{~mm} \mathrm{~K}$ while it reversed

\footnotetext{
${ }^{1}$ Abbreviations used in this paper: DPH, diphenylhydantoin ; Na-K-ATPase, sodium-potassium-adenosinetriphosphatase.
} 
ouabain inhibition of $\mathrm{K}$ transport with $50 \mathrm{~mm} \mathrm{Na}$ and $10 \mathrm{~mm} \mathrm{~K}$.

\section{METHODS}

Ficoll was obtained from Pharmacia Laboratories Inc., ouabain from Sigma Biochemicals, cesium chloride from Fisher Scientific Co, and diphenylhydantoin sodium from Parke Davis \& Company.

Preparation of synaptosomes. Synaptosomes were prepared from 18 to 26 -day old rat brain cortices (4). Synaptosomal fractions were kept in $0.32 \mathrm{M}$ sucrose and used as soon as possible. The maximum number of hours elapsed between the time of isolation and the actual experimentation was $2 \mathrm{hr}$. Synaptosomes were identified as enriched populations of nerve endings by electron microscopy and enzymespecific activity. The average yield of synaptosomal protein was approximately $2-3 \mathrm{mg} / \mathrm{g}$ wet weight of cerebral cortex.

Incubations and assessments of potassium accumulation. Incubations were performed at $23^{\circ} \mathrm{C}$ in $2 \mathrm{cc}$ containing 0.033 M of highly purified tris chloride buffer $(\mathrm{pH} 7.5) \quad 0.1 \mathrm{M}$ sucrose, $2.8-3.2 \mathrm{mg}$ of synaptosomal protein, and varying concentrations of $\mathrm{Na}$ and $\mathrm{K}$. When sodium chloride was omitted from the medium, choline chloride in equimolar concentrations was added. During assessment of DPH effects in vitro, diphenylhydantoin prepared daily, was added in specified concentrations to the reaction mixture. In all experiments, synaptosomal proteins were added at the start of incubation. Concentrations of $10^{-4} \mathrm{M}-10^{-10} \mathrm{M} \mathrm{DPH}$ did not alter the $\mathrm{pH}$ of the incubation mixture. During in vivo studies, DPH was administered intraperitoneally as a single daily dose $(40 \mathrm{mg} / \mathrm{kg}$ body weight) for a specified number of days. The animals were sacrificed $24 \mathrm{hr}$ after the last intraperitoneal dose.

The potassium content of synaptosomes was assessed by a rapid filtration technique (4). Samples $(0.2 \mathrm{cc})$ were

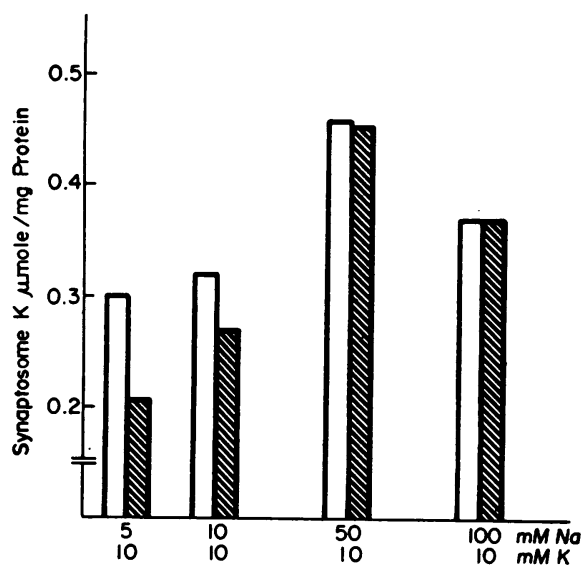

FIGURE 1 The effects of DPH on $\mathrm{K}$ accumulation within synaptosomes at varying $\mathrm{Na}$ concentrations. Synaptosomes were incubated and processed as described in Methods. Potassium (10 mM) and varying $\mathrm{Na}$ concentrations were added with (striped bars) and without $\square$ DPH $\left(10^{-4} \mathrm{M}\right)$. The total height of the bars represent synaptosomal $K$ content at 16 min incubations. Osmolarity was held constant by addition of varying concentrations of chloine chloride. The four experiments represented above were from one synaptosomal preparation. Similar results were obtained in four other synaptosome preparations.
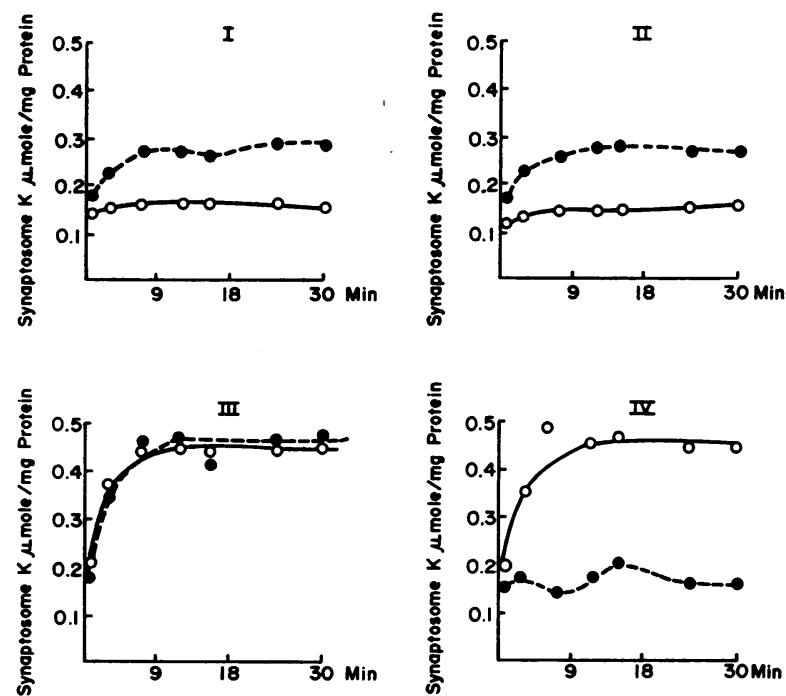

FIGURE 2 The effects of DPH on $K$ accumulation in the absence and presence of ouabain. In Panels I and II, $5 \mathrm{~mm} \mathrm{Na}$ and $10 \mathrm{~mm} \mathrm{~K}$ are present in the standard reaction mixtures. - - in Panel I represent control synaptosomes and $\mathrm{O}-\mathrm{O}-\mathrm{O}$ are synaptosomes treated with $\mathrm{DPH}$ in vitro at $10^{-4} \mathrm{M}$. In Panel II, ouabain $\left(10^{-4} \mathrm{M}\right)$ is present in while DPH $\left(10^{-4} \mathrm{M}\right)$ and ouabain $\left(10^{-4} \mathrm{M}\right)$ are present in $O-O-O$. In Panels III and IV, $50 \mathrm{~mm} \mathrm{Na}$ and $10 \mathrm{~mm} \mathrm{~K}$ are present in the incubations. - - in Panel III represent control synaptosomes and $\mathrm{O}-\mathrm{O}-\mathrm{O}-\mathrm{O} \mathrm{DPH}\left(10^{-4} \mathrm{M}\right)$ treated synaptosomes. In Panel IV, ouabain has been incubated with synaptosomes of - - DPH is present with ouabain in $\mathrm{O}-\mathrm{O}-\mathrm{O}$.

removed from the reaction mixture at appropriate times, pipetted into $5.0 \mathrm{cc}$ of ice-cold $0.25 \mathrm{M}$ sucrose, rapidly mixed by inversion, and immediately poured on a moist Millipore filter (Millipore Corp.), mounted on a suction flask. The filters were $25 \mathrm{~mm}$ in diameter and $0.45 \mu$ pore size. The mixture of sample and sucrose were suctioned through the filter until a minimal layer of fluid remained above the filter. The filters were then washed with an additional $25 \mathrm{cc}$ of $0.25 \mathrm{~m}$ sucrose and suctioned until dry. The cations were extracted from the filter by addition of $2 \mathrm{cc}$ of $1 \% \mathrm{HNO}_{3}$ containing $4 \mathrm{~mm}$ cesium chloride. The $\mathrm{K}$ content of the 2 cc extract was measured in a Perkin-Elmer atomic absorption spectrophotometer (Perkin-Elmer Corp.). Proteins were determined by the method of Lowry, Rosebrough, Farr, and Randall (5) and the $\mathrm{K}$ content was expressed in micromoles of $\mathrm{K}$ per milligram protein of synaptosomes.

The endogenous or base line $\mathrm{K}$ content of synaptosomes was measured immediately after isolation of synaptosomes. The incubation mixture without $\mathrm{Na}$ or $\mathrm{K}$ was used, and synaptosomes were added last. The test tubes were gently agitated twice and three $0.2 \mathrm{cc}$ samples were immediately pipetted into three separate $5 \mathrm{cc}$-volume test tubes containing ice-cold $0.25 \mathrm{M}$ sucrose. Subsequent steps were identical to those utilized in the filtration technique for in vitro $\mathrm{K}$ uptake experiments described above. The arithmetic mean of these three separate determinations were taken to represent endogenous synaptosomal $\mathrm{K}$ content.

The estimates of $K$ content per milligrams of synaptosome protein were variable from preparation to preparation. Ac- 
cumulation experiments in control and DPH-treated synaptosomes were performed from identical preparations making comparisons valid and reproducible. In DPH-treated preparations initial values at $\frac{1}{2} \mathrm{~min}$ points were not consistently lower during inhibition or consistently higher during stimulation; attempts at calculating rates of $\mathrm{K}$ accumulation, therefore produced inconsistent results. The per cent stimulation or inhibition in these experiments were calculated by comparing $16 \mathrm{~min}$ equilibrium points in control and $\mathrm{DPH}$ experiments. Results were essentially similar when 8 and $30 \mathrm{~min}$ incubation points were compared.

\section{RESULTS}

In vitro experiments. Previous experiments on $\mathrm{K}$ accumulation within synaptosomes have demonstrated time dependent $\mathrm{K}$ uptake to be optimal with $50 \mathrm{~mm} \mathrm{Na}$ and $10 \mathrm{~mm} \mathrm{~K}$ in the external medium. At these concentrations, ouabain produced an average $54 \%$ inhibition of net $\mathrm{K}$ accumulation (4).

The effects of diphenylhydantoin $\left(10^{-4} \mathrm{M}\right)$ on net $\mathrm{K}$ accumulation within synaptosomes were therefore initially determined with optimal $\mathrm{K}(10 \mathrm{~mm})$ and varying $\mathrm{Na}$ concentrations. DPH inhibited $\mathrm{K}$ uptake $31 \%$ with $5 \mathrm{~mm} \mathrm{Na}$ and $17 \%$ with $10 \mathrm{~mm} \mathrm{Na}$ (Fig. 1). At $5 \mathrm{~mm}$ $\mathrm{Na}$ and $10 \mathrm{~mm} \mathrm{~K}, \mathrm{~K}$ accumulation was relatively insensitive to ouabain and DPH induced inhibition of net $\mathrm{K}$ uptake occurred even in the presence of ouabain. Hence, while DPH effects on the ouabain sensitive $\mathrm{K}$ accumulation could not be assessed under these ionic conditions, ouabain insensitive $\mathrm{K}$ uptake was inhibited (Fig. 2). At higher $\mathrm{Na}$ concentrations $(50 \mathrm{~mm}$ and

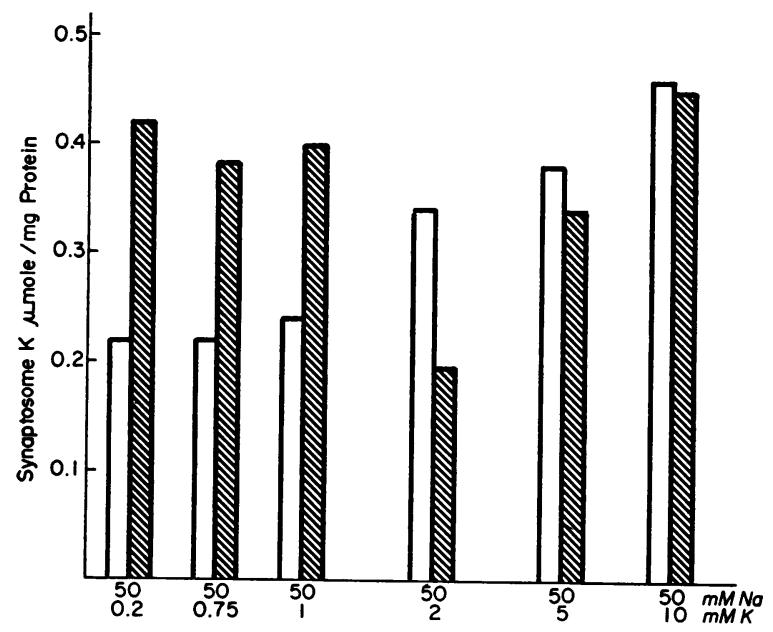

FIGURE 3 DPH effects on net $\mathrm{K}$ accumulation at varying $\mathrm{K}$ concentrations. Sodium ( $50 \mathrm{~mm}$ ) and varying $\mathrm{K}$ concentrations are present in the reaction mixtures with (striped bars) and without $\square$ DPH $\left(10^{-4} \mathrm{M}\right)$. Values obtained represent synaptosomal $\mathrm{K}$ content at $16 \mathrm{~min}$ incubations. Five experiments with one synaptosome preparation is represented. The total osmolarity was held constant by addition of varying concentrations of choline chloride. Similar results were obtained in three other synaptosome preparations.

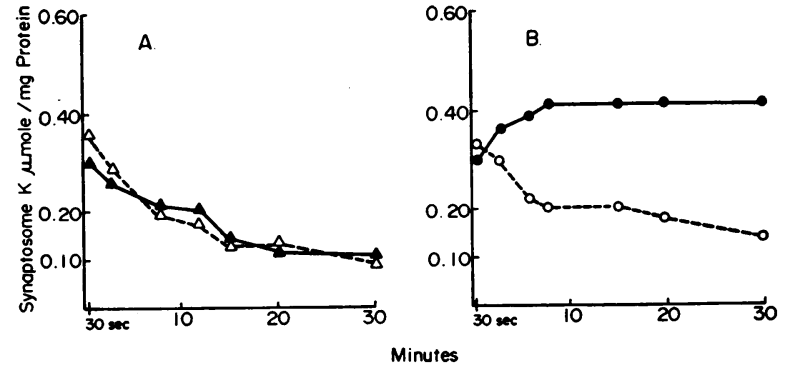

FIgURE 4 Stimulation by DPH of $\mathrm{K}$ accumulation within synaptosomes at $50 \mathrm{~mm} \mathrm{Na}$ and $0.2 \mathrm{~mm} \mathrm{~K}$. Incubations were as described in Methods. In $A, \Delta-\Delta-\Delta$ represents control synaptosomes and $\Delta-\Delta-\Delta$ synaptosomes treated with ouabain $\left(10^{-4} \mathrm{M}\right)$. In $\mathrm{B},-\longrightarrow$ represents synaptosomes incubated with DPH $\left(10^{-4} \mathrm{M}\right)$ and $\mathrm{O}-\mathrm{O}-\mathrm{O}$ synaptosomes in reaction mixtures with both $\mathrm{DPH}\left(10^{-4} \mathrm{M}\right)$ and ouabain $\left(10^{-4} \mathrm{M}\right)$.

$100 \mathrm{~mm}$ ), no significant effects on total $\mathrm{K}$ uptake was evident with DPH. However, ouabain inhibition of $\mathrm{K}$ transport which is optimum at these ionic conditions (4) were reversed by DPH. (Fig. 2).

Potassium concentrations were then varied at less than and up to $10 \mathrm{~mm}$ while $\mathrm{Na}$ was maintained at optimal concentration ( $50 \mathrm{~mm}$ ). DPH stimulated $\mathrm{K}$ accumulation $72 \%$ with $0.2 \mathrm{~mm} \mathrm{~K}, 68 \%$ with $0.75 \mathrm{~mm} \mathrm{~K}, 70 \%$ with $1 \mathrm{~mm} \mathrm{~K}$ (Fig. 3). DPH inhibited net $\mathrm{K}$ accumulation at $2 \mathrm{~mm} \mathrm{~K}(42 \%)$ and at $5 \mathrm{~mm} \mathrm{~K}(9 \%)$. At 10 $\mathrm{mm} \mathrm{K}, \mathrm{DPH}$ produced no significant effects on total $\mathrm{K}$ accumulation (Fig. 3 ).

The stimulatory effects of DPH were best appreciated when $\mathrm{K}$ accumulation was studied as a function of time. At $50 \mathrm{~mm} \mathrm{Na}$ and $0.2 \mathrm{~mm} \mathrm{~K}$ in the external medium, no $\mathrm{K}$ uptake was evident; in fact the $\mathrm{K}$ content of synaptosomes gradually declined during the first 9 min (from 0.36 to $0.21 \mu$ moles $\mathrm{K} / \mathrm{mg}$ protein). With the addition of DPH $\left(10^{-4} \mathrm{M}\right)$, the intrasynaptosomal $\mathrm{K}$ increased during the first $9 \mathrm{~min}$ from 0.3 to $0.4 \mu$ moles $\mathrm{K} / \mathrm{mg}$ protein (Fig. 4). During the subsequent $20 \mathrm{~min}$, $\mathrm{K}$ content remained unchanged at $0.4 \mu \mathrm{moles} / \mathrm{mg}$ protein. In seven separate synaptosomal preparations, DPH stimulated $\mathrm{K}$ accumulation by an average $91 \%$ with 50 $\mathrm{mm} \mathrm{Na}$ and $0.2 \mathrm{~mm} \mathrm{~K}$ in the external medium (Table $\mathrm{I})$. With no $\mathrm{K}$ and $50 \mathrm{~mm}$ sodium, $\mathrm{DPH}$ had no significant effects. However, as stated above at $\mathrm{K}$ concentrations of $0.75 \mathrm{~mm}$ and $1 \mathrm{~mm}$, DPH stimulated $\mathrm{K}$ uptake. At all concentrations of high $\mathrm{Na}$ and low $\mathrm{K}$, the stimulatory effects of DPH could be reversed by ouabain $\left(10^{-4} \mathrm{M}\right)$ (Fig. 4).

The $\mathrm{K}$ concentration was maintained at $0.2 \mathrm{~mm}$ and $\mathrm{Na}$ concentrations were varied from 0 to $100 \mathrm{~mm}$. With these conditions, DPH was found to stimulate synaptosomal $\mathrm{K}$ accumulation only in the presence of high $\mathrm{Na}$ concentration. DPH had no effects in the absence of $\mathrm{Na}$ while net $\mathrm{K}$ accumulation and ouabain inhibition of $\mathrm{K}$ 
TABLE I

The Effects of Diphenylhydantoin on Net $K$ Accumulation at $50 \mathrm{~mm} \mathrm{Na}$ and $0.2 \mathrm{m \textrm {M } K}$

\begin{tabular}{|c|c|c|c|c|c|c|c|}
\hline \multirow[b]{2}{*}{$\begin{array}{l}\text { Experi- } \\
\text { ment }\end{array}$} & \multicolumn{3}{|c|}{ Control } & \multicolumn{3}{|c|}{ DPH } & \multirow{2}{*}{$\frac{\begin{array}{c}\text { Stimula- } \\
\text { tion }\end{array}}{16 \mathrm{~min}}$} \\
\hline & $\begin{array}{l}0.5 \\
\min \end{array}$ & $\begin{array}{c}8 \\
\min \end{array}$ & $\begin{array}{c}16 \\
\min \end{array}$ & $\begin{array}{c}0.5 \\
\min \end{array}$ & $\begin{array}{c}8 \\
\min \end{array}$ & $\begin{array}{c}16 \\
\min \end{array}$ & \\
\hline & \multicolumn{6}{|c|}{ umoles $K / m g$ protein } & $\%$ \\
\hline 1 & 0.36 & 0.20 & 0.20 & 0.30 & 0.46 & 0.48 & 140 \\
\hline 2 & 0.30 & 0.18 & 0.16 & 0.15 & 0.32 & 0.33 & 105.7 \\
\hline 3 & 0.29 & 0.23 & 0.23 & 0.20 & 0.45 & 0.46 & 102.2 \\
\hline 4 & 0.34 & 0.18 & 0.17 & 0.18 & 0.33 & 0.33 & 94.0 \\
\hline 5 & 0.36 & 0.21 & 0.16 & 0.30 & 0.40 & 0.40 & 82.0 \\
\hline 6 & 0.36 & 0.30 & 0.30 & 0.30 & 0.48 & 0.48 & 60.7 \\
\hline \multirow[t]{2}{*}{7} & 0.36 & 0.31 & 0.31 & 0.26 & 0.47 & 0.48 & 53.2 \\
\hline & & & & & \multicolumn{2}{|c|}{ Mean \pm sD } & $91.0 \pm 29.3$ \\
\hline
\end{tabular}

Reaction mixtures were incubated as described in Methods. Seven experiments with seven different synaptosomal preparations are represented.

transport were enhanced $83 \%$ with $50 \mathrm{~mm} \mathrm{Na}, 44 \%$ with $100 \mathrm{~mm} \mathrm{Na}, 13 \%$ with $10 \mathrm{~mm} \mathrm{Na}$ (Fig. 5).

Previous studies on synaptosomal $\mathrm{Na}-\mathrm{K}$ activated ATPase suggested a 50:1 Na-K ratio as critical in determining the stimulatory effects of DPH (3); a similar relation was investigated with respect to $\mathrm{K}$ transport within synaptosomes. With concentrations in the external mediums of $10 \mathrm{~mm} \mathrm{Na}$ and $0.2 \mathrm{~mm} \mathrm{~K}$ (Table II) (Fig. 5), as well as $20 \mathrm{~mm} \mathrm{Na}$ and $0.4 \mathrm{~mm} \mathrm{~K}$ (Table II), minimal stimulation or no effects were observed. At $100 \mathrm{~mm} \mathrm{Na}$ and $2 \mathrm{~mm} \mathrm{~K}, \mathrm{~K}$ uptake decreased $20 \%$. Hence, a 50:1 Na-K ratio was not essential for DPH stimulation of net $\mathrm{K}$ accumulation. As shown by the above experiments (Fig. 5) (Table II), what appears optimal are a $\mathrm{Na}$ concentration of $50 \mathrm{~mm}$ and a $\mathrm{K}$ concentration less than $2 \mathrm{~mm}$. The 50:1 ratio did not appear as meaningful as the actual levels of $\mathrm{Na}$ and $\mathrm{K}$.

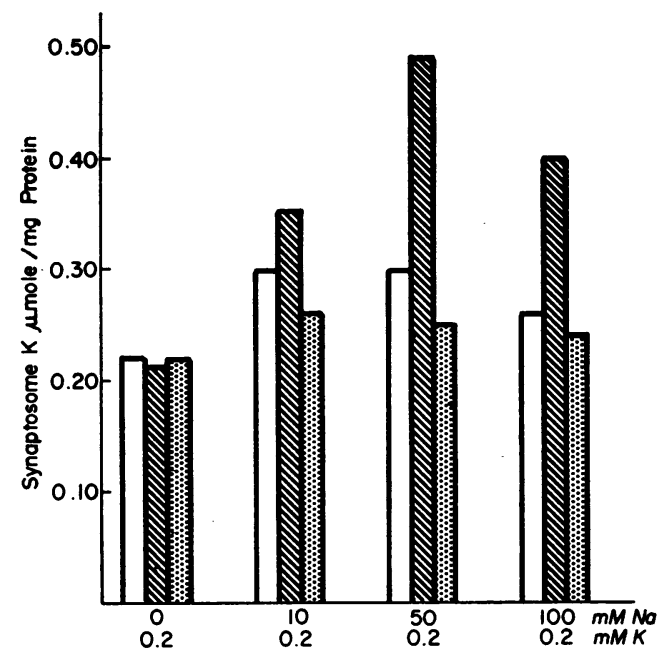

FIGURE 5 The effects of Na concentration on DPH enhanced $\mathrm{K}$ accumulation. The blocks represent $\mathrm{K}$ content at $16 \mathrm{~min}$ incubations in control $\square$ and DPH $\left(10^{-4} \mathrm{M}\right)$ treated (striped bars) synaptosomes. Ouabain $\left(10^{-4} \mathrm{M}\right)$ effects on DPH treated synaptosomes are represented by stippled bars. Osmolarity was held constant with choline chloride addition. The above experiments represent one single synaptosome preparation. Two other separate synaptosome preparations showed similar effects of $\mathrm{Na}$.

Stimulatory effects at $50 \mathrm{~mm} \mathrm{Na}$ and $0.2 \mathrm{~mm} \mathrm{~K}$ appeared over a range of $\mathrm{DPH}$ concentrations. Total $\mathrm{K}$ accumulation was enhanced $77 \%$ with $10^{-4} \mathrm{M}, 38.5 \%$ with $10^{-8} \mathrm{M}$ and $23 \%$ with $10^{-8} \mathrm{M}$, while net $\mathrm{K}$ uptake was unaltered with $10^{10} \mathrm{M}$ (Fig. 6). At $10^{-4} \mathrm{M}$ to $10^{-8} \mathrm{M}$, ouabain inhibition was enhanced to approximately the same extent total $\mathrm{K}$ accumulation was stimulated by DPH. At $10^{-10} \mathrm{M}$, ouabain inhibition increased $36 \%$ although no apparent change was observed in total $\mathrm{K}$

TABLE II

$N a / K$ Ratio and the Effects of DPH on Net $K$ Accumulation

\begin{tabular}{|c|c|c|c|c|c|c|c|c|c|}
\hline \multirow[b]{2}{*}{$\begin{array}{l}\text { Prepa- } \\
\text { ration }\end{array}$} & \multirow[b]{2}{*}{$\mathrm{Na}$} & \multirow[b]{2}{*}{$\mathbf{K}$} & \multicolumn{3}{|c|}{ Control } & \multicolumn{3}{|c|}{ DPH } & \multirow{2}{*}{$\begin{array}{c}\begin{array}{c}\text { Stimulation } \\
(+)\end{array} \\
\text { or inhibition } \\
(-) \\
\frac{16 \mathrm{~min}}{}\end{array}$} \\
\hline & & & $\begin{array}{c}0.5 \\
\min \end{array}$ & $\begin{array}{c}8 \\
\min \end{array}$ & $\begin{array}{c}16 \\
\min \end{array}$ & $\begin{array}{c}0.5 \\
\text { min }\end{array}$ & $\begin{array}{c}8 \\
\min \end{array}$ & $\begin{array}{c}16 \\
\min \end{array}$ & \\
\hline & $(\mathrm{mm})$ & $(\mathrm{mM})$ & \multicolumn{6}{|c|}{ umoles $K / m g$ protein } & $\%$ \\
\hline \multirow[t]{4}{*}{1} & 10 & 0.2 & 0.20 & 0.15 & 0.15 & 0.20 & 0.16 & 0.17 & +10 \\
\hline & 20 & 0.4 & 0.18 & 0.17 & 0.17 & 0.18 & 0.17 & 0.18 & +3.7 \\
\hline & 50 & 1 & 0.12 & 0.20 & 0.20 & 0.12 & 0.36 & 0.35 & +75 \\
\hline & 100 & 2 & 0.12 & 0.30 & 0.30 & 0.15 & 0.25 & 0.25 & -16.66 \\
\hline \multirow[t]{4}{*}{2} & 10 & 0.2 & 0.22 & 0.14 & 0.12 & 0.22 & 0.14 & 0.12 & - \\
\hline & 20 & 0.4 & 0.20 & 0.19 & 0.20 & 0.20 & 0.19 & 0.19 & -5 \\
\hline & 50 & 1 & 0.12 & 0.23 & 0.24 & 0.11 & 0.40 & 0.40 & +70 \\
\hline & 100 & 2 & 0.15 & 0.25 & 0.24 & 0.16 & 0.18 & 0.16 & -25 \\
\hline
\end{tabular}

Synaptosomes were incubated and processed as described in Methods. Eight experiments with two synaptosomal preparations are represented. 


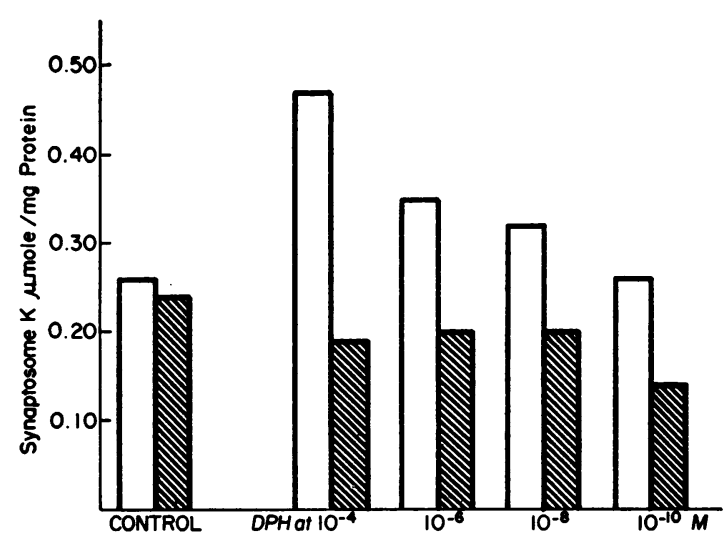

FIGURE 6 In vitro DPH concentrations and its stimulation of $\mathrm{K}$ uptake at $50 \mathrm{~mm} \mathrm{Na}$ and $0.2 \mathrm{~mm} \mathrm{~K}$. $\square$ control and DPH treated synaptosomes were incubated with (striped bars) ouabain $\left(10^{-4} \mathrm{M}\right)$. Varying concentrations of DPH were varied as indicated above. The height of the blocks represent $\mathrm{K}$ content at $16 \mathrm{~min}$ incubations. The above results were obtained from one single synaptosome preparation. Similar results were observed in four other synaptosomal preparations.

accumulation within synaptosomes (Fig. 6). Thus, the stimulatory effects of DPH are apparently mediated to a greater extent through its action on the ouabain inhibitable segment of $\mathrm{K}$ accumulation. Furthermore, it appears that under these ionic conditions, the ouabain inhibitable segment of $\mathrm{K}$ uptake is the first and most sensitive fraction affected by low concentrations of DPH.

In vivo $D P H$. The endogenous or base line potassium content of synaptosomes was not significantly changed by in vivo DPH (Table III).

The effects on $\mathrm{K}$ accumulation within synaptosomes noted with DPH in vitro were confirmed employing in vivo DPH. The in vitro accumulation of $K$ within synaptosomes was stimulated by in vivo DPH with 50 $\mathrm{mm} \mathrm{Na}$ and $0.2 \mathrm{~mm} \mathrm{~K}$ in the external medium. The increase in total $\mathrm{K}$ uptake roughly corresponded to the ouabain inhibitable segment. Significant stimulation of both total $\mathrm{K}$ uptake and its ouabain sensitive segment was observed only after two daily intraperitoneal injections (Fig. 7A). At the 2nd, 3rd, and 5th days of intraperitoneal DPH, ouabain inhibition increased approximately $60 \%$ while stimulation of total $\mathrm{K}$ accumulation varied at $85 \%$ ( 2 days) to $97 \%$ ( 3 and 5 days).

With $50 \mathrm{~mm} \mathrm{Na}$ and $10 \mathrm{~mm} \mathrm{~K}$ in the external medium, minimal or no effects on total $\mathrm{K}$ uptake were observed and ouabain inhibition in vitro disappeared or was markedly diminished with in vivo DPH (Fig. 7B).

\section{DISCUSSION}

The antiepileptic action of diphenylhydantoin has been explained by two different theories: $(a)$ that DPH stimulates the active transport of sodium and potassium either directly or indirectly; or (b) that DPH specifically blocks the passive translocation of sodium. Evidence in favor of the first theory was provided by experiments of Woodbury (1). Utilizing whole animal brains subjected to maximal electroshock seizures, he demonstrated that DPH increased $\mathrm{Na}^{22}$ turnover and decreased the electroshock (EST)-induced elevations of intracellular sodium. These results were interpreted to signify that DPH stimulated the active transport of sodium under conditions of depolarization induced by electroshock. In these experiments, no alterations were noted in potassium although a minor decrease in intracellular potassium content or a shift of $\mathrm{K}$ from neuronal to glial compartments would not have been detected by the techniques employed. In contrast to Woodbury's theory, several observations have been interpreted to support a primary blocking action of diphenylhydantoin on the downhill or passive movement of sodium ions (6-8). Experiments on lobster nerves demonstrated that DPH decreased intracellular levels of sodium with no effect on intracellular potassium; the fall in sodium content induced by DPH occurred in the presence of ouabain. These results led to the interpretation that DPH blocked the passive influx of sodium since active sodium pump mechanisms had been inactivated by ouabain.

The critical question is which of the two hypotheses best explains our results with potassium transport in synaptosomes. Our observations clearly demonstrate diphenylhydantoin enhancement of potassium uptake under two conditions: $(a)$ with $50 \mathrm{~mm}$ sodium and less than $2 \mathrm{~mm}$ potassium in the absence of ouabain, and $(b)$

TABLE III

The Effects of In Vivo DPH on Base Line $K$ Content of Synaptosomes

\begin{tabular}{|c|c|c|c|c|}
\hline $\begin{array}{l}\text { No. of } \\
\text { Daily } \\
\text { Intraperi- } \\
\text { toneal } \\
\text { DPH } \\
\text { injections }\end{array}$ & $\begin{array}{l}\text { Experi- } \\
\text { ment }\end{array}$ & Control & DPH & $\begin{array}{c}\text { Stimulation } \\
(+) \\
\text { or inhibition } \\
(-)\end{array}$ \\
\hline & & \multicolumn{2}{|c|}{ 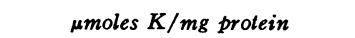 } & $\%$ \\
\hline \multirow[t]{3}{*}{1} & 1 & $0.12( \pm 0.009)$ & $0.14( \pm 0.009)$ & +9.8 \\
\hline & 2 & $0.15( \pm 0.007)$ & $0.14( \pm 0.007)$ & -6 \\
\hline & 3 & $0.22( \pm 0.005)$ & $0.22( \pm 0.004)$ & 一 \\
\hline \multirow[t]{3}{*}{2} & 1 & $0.09( \pm 0.01)$ & $0.09( \pm 0.01)$ & - \\
\hline & 2 & $0.17( \pm 0.006)$ & $0.05( \pm 0.005)$ & -12 \\
\hline & 3 & $0.08( \pm 0.012)$ & $0.07( \pm 0.009)$ & -6.6 \\
\hline 3 & 1 & $0.19( \pm 0.004)$ & $0.18( \pm 0.005)$ & -5 \\
\hline 5 & 1 & $0.27( \pm 0.002)$ & $0.27( \pm 0.004)$ & - \\
\hline
\end{tabular}

Synaptosomes were processed as described in Methods. The values represent arithmetical means and standard deviations from three determinations of intrasynaptic $\mathrm{K}$ content. DPH was administered in single doses daily for the number of days designed above. 


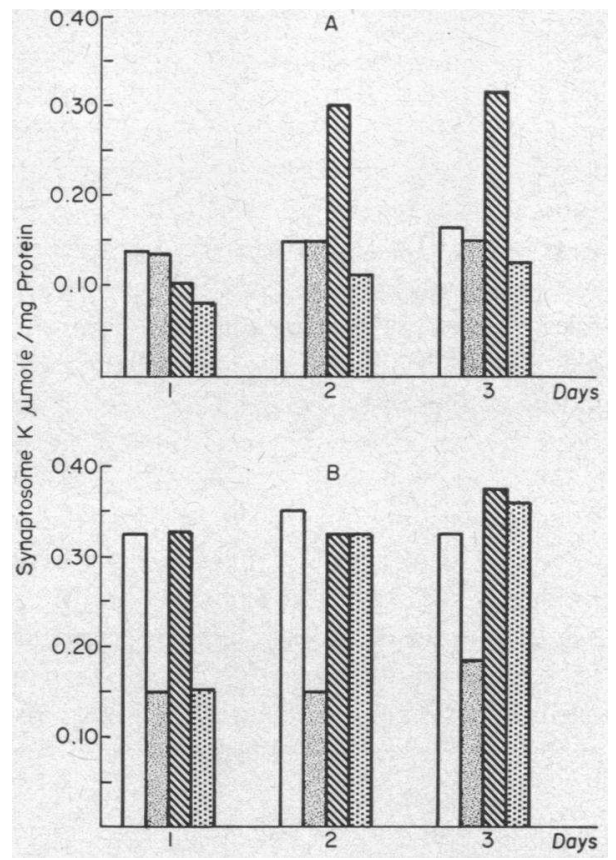

FIGURE 7 Enhancement of in vitro $\mathrm{K}$ transport after in vivo DPH. Synaptosomes were incubated and processed as described in Methods. In Panel A, incubation with $50 \mathrm{~mm} \mathrm{Na}$ and $0.2 \mathrm{~mm} \mathrm{~K}$ is performed. In Panel $\mathrm{B}, 50 \mathrm{~mm} \mathrm{Na}$ and $10 \mathrm{~mm}$ $\mathrm{K}$ is present in the reaction mixture. $\square$ represent control synaptosomes (finely stippled bars) synaptosomes with ouabain $\left(10^{-4} \mathrm{M}\right)$, (striped bars) synaptosomes from rats treated with intraperitoneal DPH and (heavily stippled bars) synaptosomes from rats which received i.p. DPH, incubated with ouabain in vitro at $10^{-4} \mathrm{M}$. DPH was administered in anticonvulsant dosages once a day for the number of days indicated above. The values represented by the entire blocks are $16 \mathrm{~min}$ incubations. Panels A and B represent six separate experiments from six synaptosomal preparations. Repeat experiments performed in 12 other synaptosome preparations showed similar effects of in vivo DPH.

with $50 \mathrm{~mm}$ sodium and $10 \mathrm{~mm}$ potassium in the presence of ouabain. These results were obtained when DPH was administered to the animals in vivo or incubated with synaptosomes in vitro. With optimal or high sodium (50-100 mM) and low potassium (less than $2 \mathrm{~mm}$ ) concentrations synaptosomes demonstrated a gradual loss of endogenous potassium content. A similar state was observed with $50 \mathrm{~mm}$ sodium and $10 \mathrm{~mm}$ potassium in the presence of ouabain. Under these conditions, DPH not only prevented potassium efflux, but also stimulated potassium accumulation to a level greater than the initial value.

It is difficult to explain these data by assuming that diphenylhydantoin simply blocked potassium efflux. Hypothetically, a block to potassium efflux should result in the maintenance of existing levels of potassium with no increase in synaptosome potassium content above initial values. Yet DPH consistently stimulated synapto- some $\mathrm{K}$ levels to higher than baseline values. The fact that ouabain could reverse the DPH induced stimulation of $\mathrm{K}$ uptake at high $\mathrm{Na}$ and low $\mathrm{K}$ concentrations offers evidence that synaptosomal sodium-potassiumATPase may be involved. These results are in agreement with previous observations that synaptosomal and microsomal sodium-potassium-ATPase is stimulated by DPH under conditions of high sodium and low potassium concentrations (9-11).

However, the action of DPH on the active transport of $\mathrm{K}$ must be reconciled with the observation that at 50 $\mathrm{mm} \mathrm{Na}$ and $10 \mathrm{~mm} \mathrm{~K}, \mathrm{DPH}$ enhanced potassium uptake in the presence of ouabain. The latter data might be explained by stimulation of $\mathrm{K}$ influx which is not dependent on sodium-potassium-ATPase. Such a transport system for $K$ could conceivably be uphill and independent of the "Na pump." In red blood cells, a second sodium pump has been used to explain sodium efflux in the presence of external sodium although this notion has recently been questioned $(12,13)$. In synaptosome fractions, the true extent to which $\mathrm{K}$ influx is insensitive to ouabain can only be defined by relating the ion movements to intracellular space volumes and further work is needed in this regard. Another way in which the present results might be interpreted and one which we favor is to consider that sodium and potassium concentrations are critical in determining the stimulatory effects of DPH and that DPH and ouabain may have similar sites of action in the synapse membrane. According to such an interpretation, the in vitro stimulation by $\mathrm{DPH}$ with $50 \mathrm{~mm} \mathrm{Na}, 10 \mathrm{~mm} \mathrm{~K}$ and ouabain results from its reversal of ouabain action; in the absence of ouabain, DPH has no significant effects at 50 $\mathrm{mm} \mathrm{Na}$ and $10 \mathrm{~mm}$ since active transport is already optimal. This interpretation is supported by our data which showed that: $(a)$ at $50 \mathrm{~mm} \mathrm{Na}$ and $10 \mathrm{~mm} \mathrm{~K}$, the effects of ouabain on $\mathrm{K}$ transport are not observed within synaptosomes pretreated in vivo with DPH; (b) $\mathrm{DPH}$ induced stimulation of $\mathrm{K}$ uptake under high $\mathrm{Na}$ and low $\mathrm{K}$ concentrations is reversed by ouabain. Previous experiments on DPH which demonstrated stimulation of Na-K ATPase activity at high sodiumlow potassium concentrations and which equally emphasized the absence of any significant effects by DPH at optimum ionic conditions, lend further support to this interpretation. These results suggest that $\mathrm{DPH}$ may lower the $K_{m}$ of potassium for the sodium-potassium-ATPase (3).

Our experiments therefore are compatible with Woodbury's hypothesis that DPH stimulates the active transport process. However, in our system this is evident only under those conditions where potassium is leaking out of the synaptosomes, a condition analogous to the depolarized state. DPH had inhibitory or no effects on 
potassium uptake within synaptosomes under other ionic conditions. Our observations do not distinguish between direct and indirect effects of $\mathrm{DPH}$ on the membrane bound Na-ATPase. However, the data suggest that the effects may be indirect and may depend upon the specific membrane structure, the conformation of the depolarized state and the ionic environment.

It is possible to reconcile the effects of $\mathrm{DPH}$ on peripheral nerves, and on synaptosomes by assuming differences in membrane structure. Some pharmacologic agents are known to affect different membranes in different ways. Tetrodotoxin blocks passive sodium conductance in peripheral nerves while it has no demonstrable effects on synapses of the stellate ganglion of the squid (14), and on frog spinal cord synapses (15). Pentylenetetrazol, a known depolarizing agent of central synapses has no effect on intracellular sodium and potassium contents of lobster nerves (7). DPH presently considered to have no effects on ion transport in red blood cells (6) may exert its major effects on passive sodium conductance in peripheral nerves while its effect on synapse membranes may depend upon its interaction with specific membrane structures including the sodium-potassium-ATPase as well as upon specific ionic conditions.

During the first $24 \mathrm{hr}, \mathrm{DPH}$ injected in vivo at regular anticonvulsant dosages, for rats had no effects on synaptosomal potassium transport in vitro. This observation is consistent with clinical studies which demonstrate that DPH at the usual clinical dosages required several days to achieve satisfactory anticonvulsant effects (16). Experimental studies show that DPH rapidly enters the cerebral cortex within minutes after intracarotid injection (17). In the cat cerebral cortex, the concentration of DPH 2 min after intracarotid injection is as high as that achieved at $30 \mathrm{~min}$ while at 24 $\mathrm{hr}$ it is only slightly lower than levels achieved at $3 \mathrm{hr}$. Similar rates of entry have recently been observed in rat cerebral cortex after intraperitoneal injection (18). The observed delay in the action of diphenylhydantoin on both synaptosomal potassium transport in vitro and clinical seizures could have similar explanations. The critical element could be that diphenylhydantoin may have to reach the synapse terminal before it can exert its effects. If diphenylhydantoin must be transported from a proximal site to the synaptic terminal, such a time lag for effectiveness may be related to the time for its appearance at the synapse.

Additional work is necessary to determine the relevance of these in vitro observations for understanding how diphenylhydantoin modifies convulsive activity in vivo. It is reasonable to suspect synaptic terminals as the sites of action for DPH in its control of seizures since the electrophysiologic expression of epilepsy con- sists of high amplitude excitatory postsynaptic potentials and dendritically originating action potentials (19). However, changes in intracellularly recorded synaptic events induced by in vivo DPH comparable with those described above have yet to be shown. Supportive evidence for DPH effects on presynaptic events might lie in the demonstration of secondary stimulation or inhibition of neurohormone release from the synaptic membranes under varying ionic conditions in the presence of DPH. Recently, such evidence has been provided by studies of pancreatic tissues and isolated islets of Langerhans where DPH modified insulin secretion through effects on cations and sodium-potassium-ATPase (20). Such studies are in accord with the hypothesis that $\mathrm{DPH}$ may act by stimulating the active transport of sodium and potassium and thereby reduce the output of transmitter associated with the convulsive state.

\section{ACKNOWLEDGMENTS}

We want to thank Mrs. Karen Harms for expert technical assistance and Donald B. Powell, the Veterans Administration Hospital, Durham, North Carolina for the medical illustrations.

This work was supported in part by grants NB-07872 and NS-06233 from the U. S. Public Health and Veterans Administration Hospital, Durham, North Carolina, and the National Multiple Sclerosis Society.

\section{REFERENCES}

1. Woodbury, D. M. 1955. Effect of diphenylhydantoin on electrolytes and radiosodium turnover in brain and other tissue of normal, hyponatremic and postical rats. $J$. Pharmacol. Exp. Ther. 115: 74.

2. Skou, J. C. 1964. Enzymatic aspects of active linked transport of $\mathrm{Na}^{+}+\mathrm{K}^{+}$through the cell membrane. Progr. Biophys. Mol. Biol. 14: 133.

3. Festoff, B. W., and S. H. Appel. 1968. Effect of diphenylhydantoin on synaptosome sodium-potassium-ATPase. J. Clin. Invest. 47: 2752.

4. Escueta, A. V., and S. H. Appel. Biochemical studies of synapses in vitro. II. Potassium transport. Biochemistry. 8: 725 .

5. Lowry, O. H., N. J. Rosebrough, A. L. Farr, and R. J. Randall. 1951. Protein measurement with the folin phenol reagent. J. Biol. Chem. 193: 265.

6. Pincus, J. H., and M. D. Rawson. 1969. Diphenylhydantoin and intracellular sodium concentration. Neurology. 19: 419.

7. Pincus, J. H., I. Grove, B. B. Marino, and G. E. Glaser. 1970. Studies on the mechanism of action of diphenylhydantoin. Arch. Neurol. 22: 566.

8. Crane, P., and P. D. Swanson. 1970. Diphenylhydantoin and the cations and phosphates of electrically stimulated brain slices. Neurology. 20: 1119.

9. Pincus, J. H., and N. J. Giarman. 1967. The effect of diphenylhydantoin on sodium-, potassium-, magnesiumstimulated adenosine triphosphate activity of rat brain. Biochem. Pharmacol. 16: 600 .

10. Lewin, E., and V. Bleck. 1970. The effect of diphenylhydantoin on cortex sodium potassium-activated ATPase. Neurology. 19: 429. 
11. Rawson, M. D., and J. H. Pincus. 1968. The effect of diphenylhydantoin on sodium, potassium, magnesiumactivated adenosine triphosphatase in microsomal fractions of rat and guinea pig brain and on whole homogenates of human brain. Biochem. Pharmacol. 17: 573.

12. Hoffman, J. F., and F. M. Kregenow. 1966. The characterization of new energy dependent cation transport processes in red blood cells. Ann. N.Y.Acad. Sci. 137: 566.

13. Lubowitz, H., and R. Whittam. 1969. Ion movements in human red cells independent of the sodium pump. $J$. Physiol. 202: 111.

14. Miledi, R. 1967. Spontaneous synaptic potentials and quantal release of transmitter in the stellate ganglion of the squid. J. Physiol. 192: 379.

15. Colomo, F., and S. D. Erulkar. 1968. Miniature synaptic potentials at frog spinal neurones in the presence of tetrodotoxin. J. Physiol. 199: 205.
16. Toman, J. E. P. 1965. Drugs effective in convulsive disorders. In The Pharmacological Basis of Therapeutics. L. S. Goodman and A. Gilman, editors. The Macmillan Company, New York.

17. Firemark, H., C. F. Barlow, and L. J. Roth. 1963. The entry, accumulation and binding of diphenylhydantoin$2-\mathrm{C}^{14}$ in brain. Studies on adult, immature and hypercapnic cats. Int. J. Neuropharmacol. 2: 25.

18. Lee, S. I., and N. H. Bass. 1970. Microassay of diphenylhydantoin: blood and regional brain concentrations in rats during acute intoxication. Neurology. 20: 115.

19. Prince, D. A. 1969. Electrophysiology of "epileptic" neurons: spike generation. Electroencephalogr. Clin. Neurophysiol. 26: 476 .

20. Kizer, J. S., M. Vargas-Cordon, K. Brendel, and R. Bressler. 1970. The in vitro inhibition of insulin secretion by diphenylhydantoin. J. Clin. Invest. 49: 1942. 